\title{
Origin of the Genus Homo
}

\author{
Holly M. Dunsworth
}

Published online: 11 August 2010

(C) Springer Science+Business Media, LLC 2010

\begin{abstract}
The origin of the genus Homo in Africa signals the beginning of the shift from increasingly bipedal apes to primitive, large-brained, stone tool-making, meat-eaters that traveled far and wide. This early part of the human genus is represented by three species: Homo habilis, Homo rudolfensis, and Homo erectus. H. habilis is known for retaining primitive features that link it to australopiths and for being the first stone tool makers. Little is known about $H$. rudolfensis except that it had a relatively large brain and large teeth compared to $H$. habilis and that it overlapped in time and space with other early Homo. Our understanding of the paleobiology and evolution of the larger-brained $H$. erectus is enhanced due to its rich fossil record. H. erectus was the first obligate, fully committed biped, and with a body adapted for modern striding locomotion, it was also the first in the human lineage to disperse outside of Africa. The early members of the genus Homo are the first to tip the scale from the more apish side of our evolutionary history toward the more human one.
\end{abstract}

Keywords Paleoanthropology $\cdot H o m o \cdot H$. habilis . $H$. rudolfensis $\cdot H$. erectus . Pleistocene - Oldowan . Acheulean $\cdot$ Bipedalism $\cdot$ Encephalization

\section{Introduction}

For the first, four million years or so of hominin evolution, the hominin fossil record is characterized by, among other

H. M. Dunsworth $(\bowtie)$

Department of Anthropology, Northeastern Illinois University,

5500 N St. Louis Ave,

Chicago, IL 60625, USA

e-mail: h-dunsworth@neiu.edu trends, canine reduction and postcranial metamorphosis in the following genera: Sahelanthropus, Orrorin, Ardipithecus, Australopithecus, and Paranthropus. As the Pliocene epoch came to a close and global climate was shifting at about 2.5 million years ago (deMenocal 2004), there is a concomitant change in the hominin fossil record. In this increasingly cooler world, something new, both anatomically and behaviorally, emerged. This is the origin of the genus Homo.

Of the earliest members of the genus Homo, the bestknown species are Homo habilis, Homo rudolfensis, and Homo erectus (Table 1). Listed roughly in order of their earliest appearance from oldest to youngest, these three species are the focus of this review. The first two species are the most primitive. Compared to what is known about H. erectus, little is known about how they differ in anatomy and behavior from one another and from preceding australopiths. Although it was anatomically and behaviorally primitive compared to modern humans, $H$. erectus signifies a major shift in hominin evolution, most notably through increased brain and body size and increasingly complex tools and behaviors.

It is generally agreed upon that $H$. habilis, spanning from 2.3 to 1.4 million years ago, is descended from a species of Australopithecus. If $H$. habilis evolved in East Africa, then Australopithecus afarensis and Australopithecus garhi are its possible ancestors, but if $H$. habilis evolved in South Africa, then Australopithecus africanus and Australopithecus sediba are candidates. Future fossil discoveries will probably answer this question. However, based on what is already known about $H$. habilis, it widely accepted that it is the common ancestor of all later species in the genus Homo including our own, Homo sapiens.

H. habilis and H. rudolfensis - the poorly understood, but slightly larger species dated to about 1.9 million years ago 


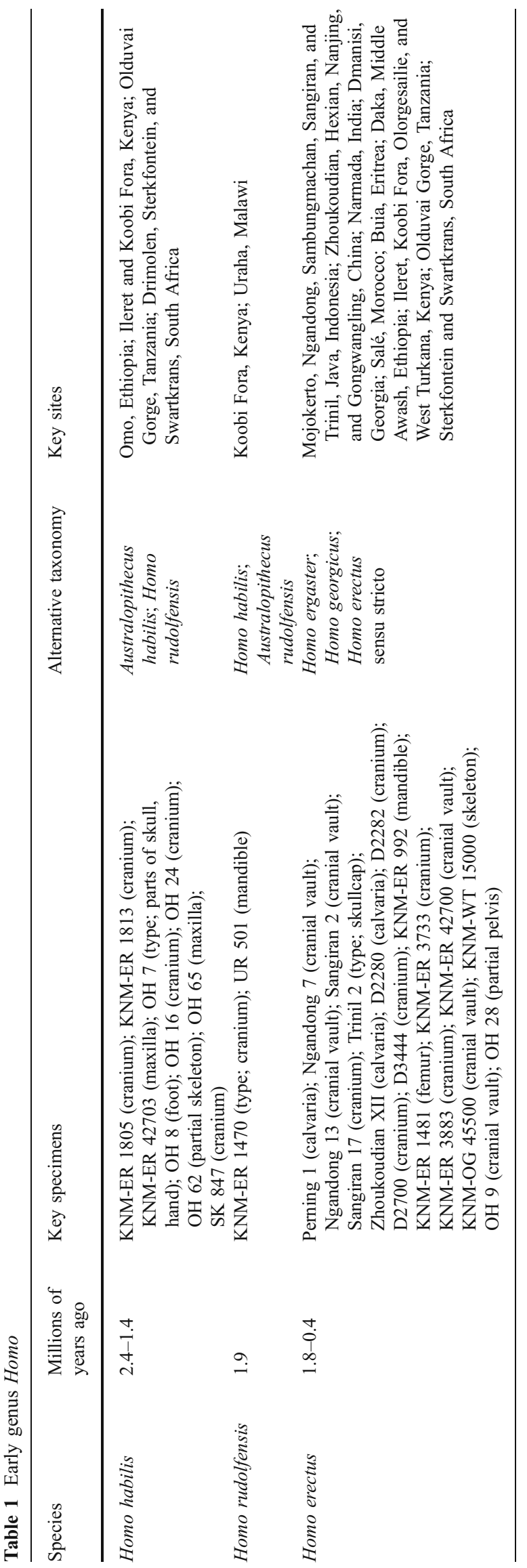

(Fig. 1) - are restricted to East and South Africa. However, $H$. erectus, which diverged from $H$. habilis around 1.8 million years ago, marks the first hominin to disperse outside of Africa. Between about 1.9 and 1.8 million years ago, there is evidence for geographic and temporal overlap of all three early Homo species in East Africa.

The exceptionally large-toothed and strong-jawed robust australopiths (Paranthropus, which also descended from an earlier Australopithecus species), with their distinct dietary niche, one of tough nuts, seeds and fruits and fibrous vegetation, continued to thrive in some of the same localities as these species of early Homo, but they remained evolutionarily separate. Early Homo is distinguishable from contemporaneous robust australopiths by their smaller teeth and jaws and by larger cranial capacity.

Because it is more derived, $H$. erectus is more easily distinguished from earlier hominins and Paranthropusnot just in craniodental anatomy but in body proportions and postcranial morphology as well. $H$. erectus is nearly modern in its postcranial anatomy, with few exceptions. Within Africa, early $H$. erectus overlapped with the two other species of early Homo but eventually far outlasted them. Outside of Africa, H. erectus fossils are the most primitive hominins yet discovered, and remains have been recovered from sites across Eurasia and Indonesia, beginning as early as about 1.8 million years ago and spanning over one million years, disappearing in Asia by about 400 thousand years ago (Shen et al. 2009). It is possible that the last $H$. erectus may have survived in Indonesia as recently as 30,000 years ago (Swisher et al. 1996), after H. sapiens had already reached the region, but this date is controversial and may be soon replaced by a much older estimate of about 550,000 years ago (Indriati et al. 2010). Regardless of its extinction date, H. erectus
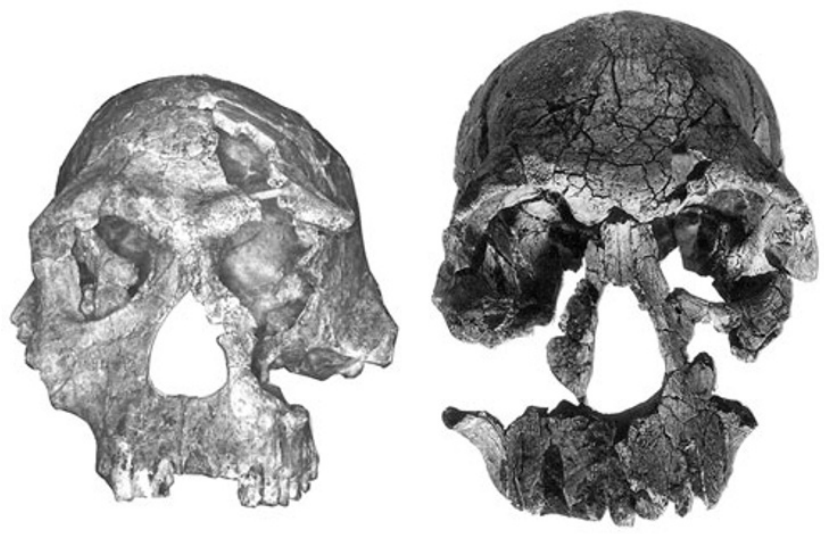

Fig. 1 Both found in the early 1970s at sites at Koobi Fora, Kenya, these skulls, from left to right, of $H$. habilis (KNM-ER 1813) and $H$. rudolfensis (KNM-ER 1470) represent the variation in size exhibited by early Homo. Photographs by Alan Walker 
thrived and evolved across the tropical and temperate regions of the Old World with a much wider geographic distribution than any preceding hominins.

As with so many mammalian extinctions in the Pleistocene fossil record, it is unclear why $H$. erectus did not survive to the present day, except that later species of Homo had much bigger brains, much more sophisticated technology, and either indirectly or directly out-competed $H$. erectus at being big-brained, bipedal, stone tool-making hominins.

Because the fossil record is denser for this species, the variation in $H$. erectus is better understood than in any of the earlier hominins. A growing proportion of researchers employ a separate species name for the earliest members of $H$. erectus that tend to be smaller and are found mostly in Africa; they call these Homo ergaster (Tattersall 2007; for discussion see Dunsworth and Walker 2002). This scheme implies that $H$. ergaster in Africa is ancestral to, or is a sister group to, H. erectus in Asia. However, in this review, large-brained, large-bodied members of the genus Homo found across the Old World are considered to display regional, not species-level, variation, and are all described as $H$. erectus (following Antón 2003). Under this hypothesis, regional variation in $H$. erectus cranial features and body size, as in $H$. sapiens, are the result of drift, gene flow, and selection working differently in geographically dispersed populations.

The evolutionary lineage leading to later Homo, including Neanderthals and $H$. sapiens, split from a population of $H$. erectus, probably living in Africa. With future fossil discoveries across the Old World, this geographic interpretation for $H$. erectus origins may change, but the phylogenetic hypothesis for its relationship to humans is unlikely to be overturned soon.

\section{Identification and Morphology}

The genus Homo originated some time between 3.0 and 2.5 million years ago (Grine and Fleagle 2009). Although there are no definitive specimens of Homo from this time period, the Homo lineage most likely diverged in Africa because the earliest putative Homo fossils are all African.

Candidates for earliest Homo (Kimbel 2009) include (a) Sts 19, a cranial fragment from Member 4 at Sterkfontein, South Africa dated to about 2.7-2.5 million years ago; (b) KNM-BC 1, a temporal bone fragment from the Chemeron Formation in Kenya dated to about 2.4 million years ago; (c) UR 501, a mandible with teeth from Uraha, Malawi dated to between 2.5 and 1.9 million years ago; (e) A.L. 666-1, a maxilla with teeth from the Hadar Formation in Ethiopia dated to about 2.3 million years ago; (f) teeth from the Shungura Formation, Ethiopia, dated to about 2.4-2.0 million years ago; (g) a partial cranium with teeth (attributed to A. garhi; Asfaw et al. 1999) and associated limb bones from the Hata Member, Bouri Formation of Ethiopia, dated to about 2.5 million years ago.

Another candidate for earliest Homo has recently been announced. The remains of two partial skeletons from Malapa, South Africa, dated to 1.9 million years ago, have been attributed to A. sediba (Berger et al. 2010), but their Homo-like traits (e.g., small premolars and molars and derived bipedal traits in the pelvis and legs) beckon researchers to test the hypotheses that these finds belong either to the ancestor of Homo or to the genus Homo.

None of the candidates for earliest Homo lands firmly in the known range of anatomical variation for $H$. habilis, $H$. rudolfensis, or $H$. erectus. However, they all show arguable links to the genus Homo and arguable differences from australopiths. Without the discovery of more fossils, these issues will not be resolved easily (Fig. 2).

In 1964, Louis Leakey, Philip Tobias, and John Napier were the first to tackle the question of where Australopithecus ends and Homo begins (Leakey et al. 1964). The discovery of some associated cranial fragments, a mandible, and wrist and hand bones $(\mathrm{OH} 7$; see Susman 2008) from Bed I of Olduvai Gorge, dated to about 1.75 million years ago, spurred these authors to carve out a definition of the genus Homo that accounted for its primitive beginnings in a brand new species $H$. habilis. Until this time, there were no specimens of early Homo on record that were more primitive than $H$. erectus. Subsequently, there was a flood of early Homo discoveries in East Africa (Leakey 1961, 1971, 1973a, b, 1974, 1976; Leakey and Leakey 1964; Day 1971; Leakey et al. 1971; Leakey and Wood 1973; Day and Leakey 1974; Day et al. 1975; Johanson et al. 1987). These new fossils contributed to the wide acceptance of $H$. habilis, but not until after 15 years of resistance (Tobias 2009).

Leakey, Tobias, and Napier argued that what they had found was not as large-brained or bodied as $H$. erectus, a species which was poorly known at the time, but it was not as primitive and apelike as the australopiths either. Thus, they laid some ground rules for what constituted the genus Homo. First of all, brain size had to be above 600 cubic centimeters, which is greater than in all known australopiths, as understood both then and now (Holloway 2000). Plus, the bones of the skull had to be smooth and rounded, lacking the crests displayed on australopiths.

Beyond cranial morphology, the second criterion for belonging to the genus Homo, they argued, should be stone tool-making ability, which indicates an increase in behavioral and cognitive complexity associated with the larger brain. Although no one has discovered a fossil hominin skeleton holding a stone tool, those found near fossil hominins are attributed to them. 


\begin{abstract}
Among the several candidates for earliest Homo, arguably the best is the maxilla or upper jaw, A. L. 666-1, from the Afar region of Ethiopia. Dating to 2.33 million years ago, A.L.666-1 is more similar to later dental specimens deemed Homo than to those of Australopithecus or Paranthropus (Kimbel et al. 1996).

However, there is an even earlier specimen that is a contender for oldest Homo: KNM-BC 1, from the site of Chemeron in the Baringo region of Kenya. It is merely the part of the temporal bone of the skull with the external auditory meatus (the ear hole) and the mandibular joint preserved. Normally, a small, isolated, and broken fossil gets little attention, but this one has seen decades of debate thanks, in large part, to its date of about 2.4 million years ago (Deino and Hill 2002), which coincides with the disappearance of australopiths in East Africa.

Initially, KNM-BC 1 was described as simply an indeterminate species within the family Hominidae (Tobias 1967), but this has been followed by a cascade of interpretations including $A$. africanus (Howell 1972, 1978), Australopithecus cf.boisei (Day 1986), Paranthropus boisei (Tobias 1991), Homo (Hill et al. 1992), H. habilis or H. rudolfensis (Wood 1999; Sherwood et al. 2002), Homo (Sherwood et al. 2002), Australopithecus (Paranthropus) species indeterminate (Lockwood et al. 2002), and also Paranthropus aethiopicus, A. garhi (which has been hypothesized to be ancestral to Homo; Kimbel 2009; Asfaw et al. 1999), or Homo (Dunsworth 2002). The debate over KNM-BC 1 does not symbolize the incompetence of paleoanthropologists. Instead, it illustrates the need for more fossils since there are few specimens on record with the same anatomy preserved for comparison. Furthermore, it highlights the difficulty in distinguishing the earliest members of the genus Homo from australopiths.
\end{abstract}

Fig. 2 Hard to find and even harder to recognize

Leakey and colleagues also suggested that the face and mandible of the genus Homo should be smaller than australopiths, more like $H$. erectus and $H$. sapiens and that the postcranial skeleton should resemble H. sapiens (few postcranial elements of $H$. erectus were known at the time). The partially preserved foot skeleton $(\mathrm{OH} 8)$ showed that $H$. habilis had fully adapted feet for walking bipedally, unlike preceding australopiths, which still had some primitive traits (like a slightly divergent big toe) despite their regular upright locomotion.

These standards were useful at a time when the fossil record was sparse and, thus, told a simpler story. But now that the fossil record has grown and the picture has become much more complex, these first standards for early Homo are no longer as effective for sorting out which fossils belong to the genus Homo and which belong to other genera.

Part of the difficulty lies in the parts preserved. None of the late Pliocene candidates for earliest Homo preserves the means for estimating brain size, so there is no way of tracking brain size expansion in the fossil record at this time. Moreover, the only two candidates for earliest Homo that preserve postcranial elements have already been attributed to Australopithecus despite the presence of some derived anatomical trends compared to australopiths (e.g., the humanlike humerofemoral length index of the Bouri remains; Asfaw et al. 1999). The only candidate for earliest Homo to be recovered in loose association with stone tools (not the tools themselves, but butchered bones) has been attributed to Australopithecus. This behavioral criterion may be the weakest of all of the original standards since the earliest tools on record, from as early as 2.6 million years ago in Gona, Ethiopia (Semaw et al. 1997, 2003), predate the candidates for earliest Homo by at least 100,000 years. What is more, the earliest stone tools do not exactly track brain size evolution since they predate the earliest evidence for significantly larger brains by at least 700,000 years.

Drastic changes - such as the full-body adaptation to bipedalism and the development of a larger brain —-would be more conspicuously played out in the fossil record if more creatures were preserved as complete individuals. In reality, paleontologists are given only bits and pieces with which to reconstruct the experiment that nature performed millions of years ago. As a result of the imperfect preservation of the fossil record, most specimens of early Homo are teeth, jaws, and skull fragments, the anatomy of which cannot directly or easily speak to bipedalism or brain size.

Teeth are the most abundant items in the fossil record. Tooth enamel is made of a durable substance, hydroxyapatite, which is much better at withstanding the chemical and physical degradation that occurs during the fossilization process than bones are. Fortunately, teeth also evolve and adapt relatively rapidly, so paleontologists can use tooth morphology to diagnose species-like $H$. habilis, $H$. rudolfensis, and $H$. erectus - without needing to find complete skulls or entire skeletons.

To recognize that a tooth or jaw from the late Pliocene and onward is a member of the genus Homo and not Australopithecus or Paranthropus, it must be more humanlike and less apelike than those genera. This suite of traits includes smaller teeth overall, relatively smaller molars and premolars compared to the incisors, further reduced canines than earlier hominins, thick enamel, and a parabolic dental arcade. That is, the teeth form a horseshoe shape rather than a v-shape or a u-shape, as in earlier hominins and in nonhuman apes. As described below, particular features of the dentition, the jaws, the cranium, the cranial capacity, and the postcranial morphology distinguish $H$. habilis, $H$. rudolfensis, and $H$. erectus from one another.

\section{Homo habilis}

H. habilis was a small-bodied biped, with a brain larger than Australopithecus and Paranthropus, averaging over 600 cubic centimeters. However, because of some crania 
like KNM-ER 1813 which has a cranial capacity of only 510 cubic centimeters, the range of variation overlaps with the other genera (Holloway 1983; Miller 1990).

Despite its small brain size, KNM-ER 1813 shares features with other, larger-brained cranial representatives of $H$. habilis (e.g., OH 24) that characterize the species: the roundness of the brain case, the small size of the orbits, and the degree of prognathism or projection below the nose, which is still more pronounced in H. habilis than in later Homo. Like its australopith ancestors, H. habilis still had large teeth, some specimens rivaling australopiths, but the molars are narrower and the third molars are reduced in size (Wood 1992).

Body size and limb proportions that have been reconstructed from the partial $H$. habilis skeleton from Olduvai Gorge (OH 62; Johanson et al. 1987) are unlike H. erectus (Larson 2009). However, this individual is so fragmentary that it is often disregarded in analyses of hominin body size (Jungers 2009). In general, body mass estimates are difficult to make, given the paucity of postcranial fossils for this species, but a generally accepted estimate is 34 kilograms ( 75 pounds), and this is smaller than estimates for Australopithecus and Paranthropus (which fall between 36 and 44 kilograms or 79 and 97 pounds) and are much smaller than those for $H$. erectus (which fall between 56 and 75 kilograms or 123 and 165 pounds; Ruff et al. 1997).

This small-bodied species also had long arms and retained some features seen in earlier hominins, linked to remnant arboreal behaviors. Shoulder elements from Olduvai Gorge (OH 48) and Koobi Fora (KNM-ER 3735) show that $H$. habilis retained primitive australopith-like morphology and was unlike all other Homo (Larson 2009). That the postcranial morphology of $H$. habilis is not humanlike, nor is it even $H$. erectus-like, is the reason why debate persists over its degree of arboreality and its adaptations for climbing (Ruff 2009; Carlson et al. 2010).

\section{Homo rudolfensis}

Very little is known about $H$. rudolfensis. The species is only represented by a toothless cranium from Koobi Fora, Kenya (KNM-ER 1470) and a mandible from Malawi (UR 501). The cranial capacity of KNM-ER 1470 is estimated at 752 cubic centimeters (Holloway 1983), and although the teeth are not preserved, the alveoli (or tooth sockets) are large, reflecting the large teeth they once contained. Some postcranial elements have been attributed to the species by some researchers, but there is weak general support for this practice. As more and more $H$. habilis and $H$. erectus fossils are discovered, there are increasing calls for KNM-ER 1470 to be subsumed into $H$. habilis (Fig. 3) and the status of $H$. rudolfensis as a valid, distinct species of early Homo is open for debate (Tobias 2009; Baab 2008a). Future discoveries will certainly help answer questions about this species.

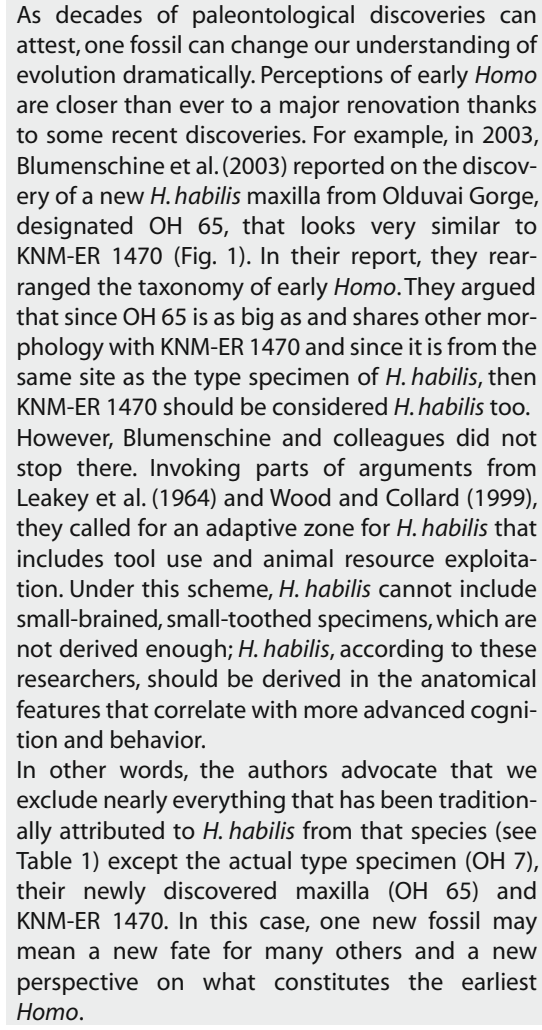

Fig. 3 Does one new discovery mean all new textbooks?

\section{Homo erectus}

Determined to find the "missing link", Dutch anatomist Eugene Dubois discovered the first remains of $H$. erectus along the Trinil River on the island of Java, Indonesia (Dubois 1894, 1924). Formerly called Pithecanthropus erectus, the skull cap (just the top of the brain case and the browridges) looked small and primitive, especially since there were no australopiths yet on record with which to compare it (see Dunsworth and Walker 2002). However, the femur that was associated with the skull cap clearly belonged to an erect, large-bodied hominin.

Subsequent to Dubois' expedition, many more $H$. erectus fossils have been collected from Indonesia (e.g., Sartono 1972), China (e.g., Black 1927, 1933; Weidenreich 1943, 1944), as well as from East, South (e.g., Clarke et al. 1970; Hughes and Tobias 1977), and North Africa (e.g., Arambourg 1954, 1955; Arambourg and Biberson 1956), Georgia (Gabunia and Vekua 1995; Gabunia et al. 2000; Lordkipanidze et al. 2005, 2007; Rightmire et al. 2006), and possibly India (Sonakia 1984). However, far and away the best single specimen of $H$. erectus is a nearly complete skeleton of a boy from the site of Nariokotome in West Turkana, Kenya (Brown et al. 1985; Walker and Leakey 1993; Fig. 4). 


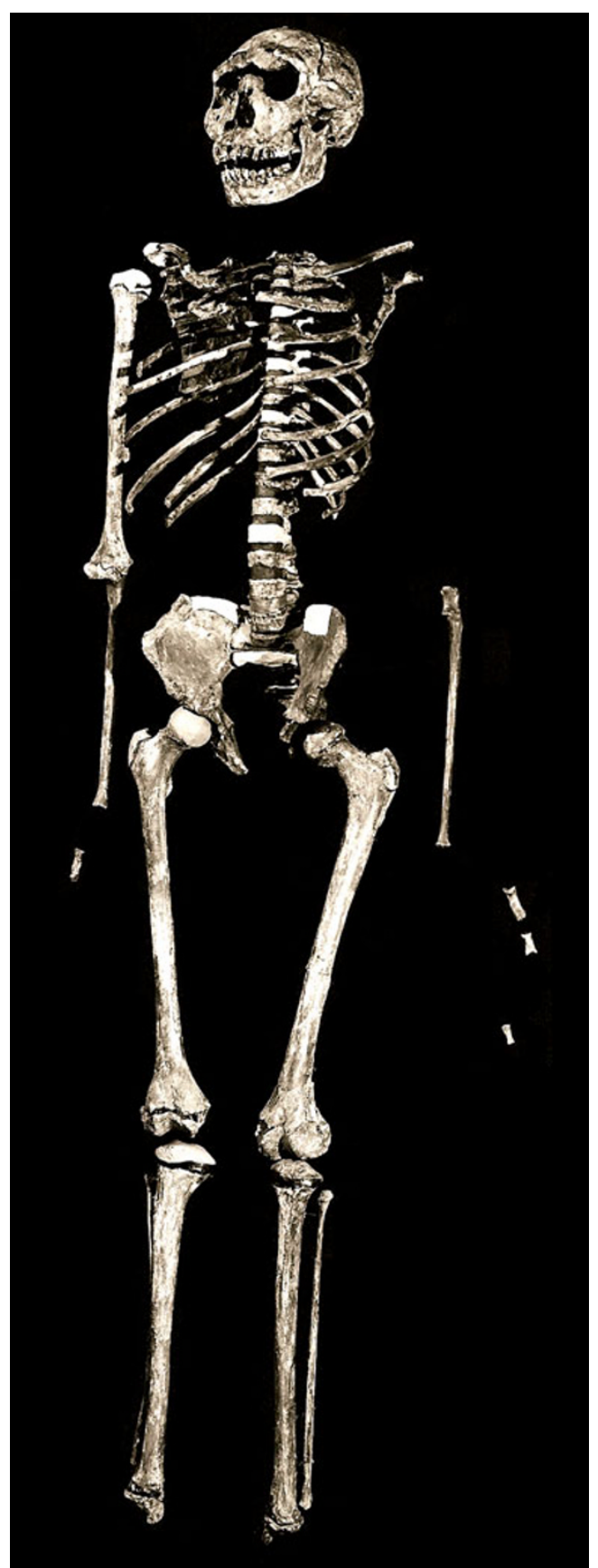

Fig. 4 The nearly complete skeleton of a young $H$. erectus, KNMWT 15000, known as the "Nariokotome boy" and also the "Turkana boy" was discovered by Kamoya Kimeu on the west side of Lake Turkana, Kenya (across the water from Koobi Fora) in the early 1980s. Photograph by Alan Walker

With larger bodies, larger brains, and smaller teeth, most $H$. erectus fossils are distinct from the other two species of early Homo. H. erectus teeth are smaller than H. habilis and $H$. rudolfensis, and although the early specimens have large teeth, tooth size decreases through time in the species. The upper incisors of many specimens are shovel-shaped, and this is seen in some modern humans.
H. erectus crania are distinct from H. habilis first and foremost by their larger brain size $(700-1,300$ cubic centimeters), which begins small and increases through time. They have a thicker browridge which sometimes forms a bony shelf called a supra-orbital torus, and the frontal bone, above the browridge, recedes toward the back. The overall shape of the $H$. erectus cranium is long and low (like an American football) compared to a round H. sapiens cranium (which is relatively more like a soccer ball), and the widest breadth of the $H$. erectus cranium is near the ears, which is lower than it is in humans. H. erectus also has a strong torus on the occipital bone at the back of the skull and sometimes has a bony keel running up through the middle of the frontal bone and/or the sagittal suture on the top of the skull. In general, the bones of $H$. erectus crania are very thick and nearly twice as thick as $H$. sapiens. Asian $H$. erectus (or "H. erectus sensu stricto") crania display the above-described cranial architecture more prominently and, as a group, more than $H$. erectus from other parts of the world. These embellished cranial keels and tori could be developmentally linked to the enhanced brain size that occurs in Asian H. erectus (Spoor et al. 2007).

Although he was not fully grown, the skeleton of the Nariokotome boy (KNM-WT 15000) has provided much insight into the paleobiology of $H$. erectus (Dean and Smith 2009). According to the pattern of ossification of the ends of his long bones (also known as the fusion of his growth plates), his age at death is estimated to have been at 13 years old. However, the microscopic growth increments in his teeth indicate that he was only 8 years old when he died. Together, this evidence suggests that $H$. erectus grew up faster than $H$. sapiens (but slower than apes) and therefore achieved benchmarks of growth earlier than modern humans. Moreover, the $H$. erectus growth curve probably lacked the slowdown, followed by an adolescent growth spurt, typical in humans. The Nariokotome boy, at 8 years old, was probably as behaviorally independent and mature as a young human adult, not an 8-year-old human, so $H$. erectus had a life history unlike anything alive today (Dean and Smith 2009).

Standing about 160 centimeters (which is five feet three inches; but for a shorter estimate, see Ohman et al. 2000), he weighed an estimated 50 kilograms (about 100 pounds). Depending on the growth model used, as an adult, he may have stood 163 centimeters (five feet four inches) tall and weighed 56 kilograms (123 pounds; Graves et al. 2010), which is in line with estimates from adult $H$. erectus specimens $\mathrm{OH} 28$ and Trinil of about 57 kilograms. However, on the other end of the spectrum in this debate which is currently unfolding, he is hypothesized to have much more growth to achieve, and by adulthood, and he would have stood 175 centimeters (five feet nine inches) and weighed 75 kilograms (165 pounds; Gibbons 2010). 
The shoulder anatomy of KNM-WT 15000 shows a more humanlike orientation of the glenoid fossa of the scapula. That is, it is less cranially oriented like in earlier hominins and apes (a feature that is linked to climbing and brachiating (or arm-swinging) in trees), but because the clavicle is relatively short, the angle of the shoulder joint is still different than in modern humans. Instead of facing laterally (as in humans), the glenoid fossa in $H$. erectus is anteriorly oriented (Larson 2009). Although manipulation would not be hindered, the range of motion at the shoulder may have been limited by this scapular configuration combined with the low level of humeral head torsion. This is new, strong evidence against the notion that $H$. erectus could throw like a modern human (Larson 2009), as discussed by earlier workers (Calvin 1983; Bingham 1999; Dunsworth et al. 2003).

\section{Behavior}

Encephalization (an increase in brain size relative to body size) is a well-known trend in many evolutionary lineages. However, no other lineage experienced the degree of encephalization seen in humans today. This trend began in early Homo and is exhibited throughout the evolution of $H$. erectus. Hypotheses for encephalization in Homo include environmental pressure, predator pressure, social pressure, the opportunities created by dexterous hands, freed from a locomotor role, dietary pressure, the nutritional opportunities created by the increase of meat and marrow in the diet, or a combination of factors. No matter what the selective pressures were, increased brain size is associated with increased behavioral complexity.

The best evidence for behavior complexity in early Homo comes from the archaeological remains and artifacts associated with hominin fossils. H. habilis, the so-called "handyman," as the Latin name is translated, is credited as the first tool maker. These hominins fashioned primitive stone implements, which are dubbed the Oldowan industry for their initial discovery in Olduvai Gorge. Crude Oldowan artifacts, like choppers, flakes, cores, and hammerstones, are rarely associated with zooarchaeological evidence for carnivory (Roche et al. 2009). Moreover, for obtaining meat, early Homo probably scavenged animal carcasses more than it hunted prey. The geographically and temporally widespread use of Oldowan and eventually Acheulean tools suggests that they were used for much more than butchery (Roche et al. 2009). For example, stone tools would have been useful for obtaining and processing plant materials as well. The Oldowan industry, although primitive and simple, showed changed through time and variation in flake production (Roche et al. 2009; Braun et al. 2008a, b), especially through the technological transition to the Acheulean tradition.
Manufacturing tools out of stones is a behavior that no one has been able to link definitively to early Homo to the exclusion of other hominins. Paranthropus fossils are found at some $H$. habilis sites like those at Olduvai Gorge. Paranthropus may have had the necessary hand anatomy for gripping stones and stone tools precisely and strongly enough to make them and to use them just like Homo. However, there is no clear evidence that the genus regularly engaged in stone tool-making behavior, and this notion is supported by the lack of impact that the extinction of Paranthropus made on the archaeological record (Roche et al. 2009).

To make matters more complicated, the earliest stone tools were discovered from 2.6 million year-old sediments in Gona, Ethiopia (Semaw et al. 2003), and cut-marked bones were collected near the remains of $A$. garhi in Ethiopia (de Heinzelin et al. 1999), preceding the earliest Homo specimens by at least 100,000 years. Of course none of this evidence definitely attributes Oldowan stone tool production to australopiths, but it does put the onus on paleontologists to find earlier specimens of $H$. habilis, if the species can continue to claim the distinction of first stone tool maker.

Following the Oldowan, stone tools became more diverse and more complex or difficult to manufacture, and the tradition was in full swing by about 1.5 million years ago. This next technological phase in the lithic record is the Acheulean, and $H$. erectus is best associated with these tools in Africa. This new technology features, for example, teardrop-shaped bifaces called "handaxes" (Fig. 5). Showing no signs that they were hafted to handles, yet being circumscribed with sharp edges, handaxes were probably used to process plant materials and to skin and butcher animals. The small, delicate but sharp flakes that were produced during handaxe production were perfect for

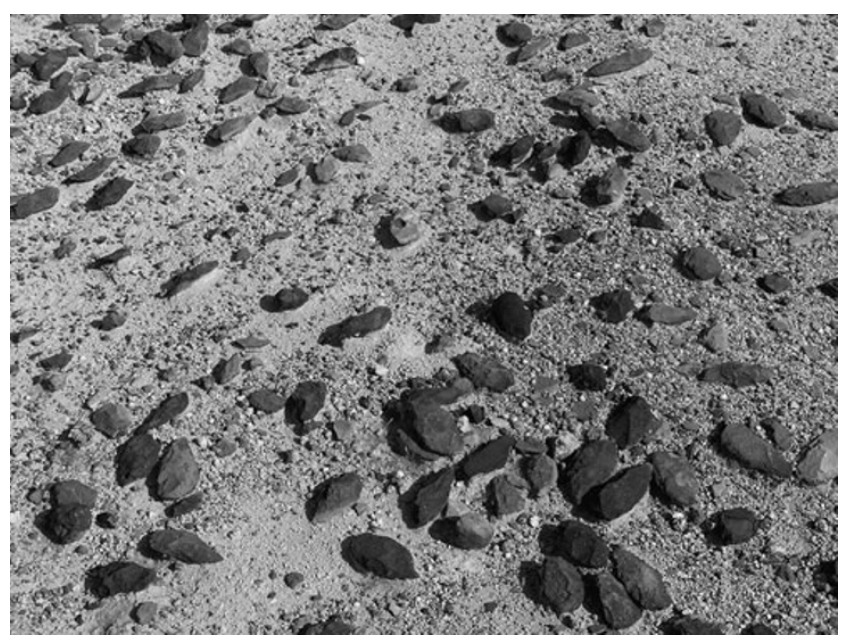

Fig. 5 Acheulean tools litter the landscape at the early Pleistocene site of Olorgesailie located in the Great Rift Valley of Kenya. Photograph by the author 
squeezing between thumb and forefinger in fine, precision cutting maneuvers.

The more advanced Acheulean tools - named for the site in France where they were initially discovered - are much more difficult to create than Oldowan tools, which look like bashed rocks to non-experts, despite the intention and cognitive power behind their creation. Acheulean bifaces, handaxes, and cleavers, on the other hand, are impossible to dismiss as mere broken rocks and are linked to increased cognitive and behavioral complexity in the hominins that made them.

Handaxes are not found at the early Pleistocene $H$. erectus sites of Dmanisi, Georgia. In fact, they are rarely found east of India despite the success of $H$. erectus in these regions. Perhaps the $H$. erectus that dispersed to East and Southeast Asia left before the technology was adopted in the west. Perhaps these hominins took up different traditions using raw materials that do not preserve as well. For now the debate continues about this east-versus-west phenomenon, which is divided by the "Movius Line" named after the archaeologist who first observed the pattern (Movius 1948). However, handaxes, or at least handaxelike artifacts, recovered from Chinese sites dating to about 800 thousand years ago complicate the picture (Hou et al. 2000; Wang et al. 2008; Petraglia and Shipton 2008; Norton [Bae] and Bae 2008).

With the improvement in stone tool technology, there is also anatomical evidence that $H$. erectus underwent a dietary shift toward increased carnivory. The cusps on $H$. erectus molars are steeper than those in australopiths, and this dental topography would have been useful for shearing meat (Ungar 2004) or fracturing tough foods in general (Unger and Scott 2009). The evidence from studies of dental microwear, though, does not fully support that early Homo was eating a diet of tough foods. In general, however, dental evidence is consistent with a diet that was variable according to the variable environments in which these hominins were living (Unger and Scott 2009).

As mentioned above, the Plio-Pleistocene transition marks a sweeping change in the East African environment, caused by global climate changes (deMenocal 2004; Maslin and Trauth 2009). Pulses of climate variability during this period are hypothesized to be linked to species turnover in the mammalian fossil record and to the evolution, variation, and adaptation of Plio-Pleistocene hominins (Maslin and Trauth 2009; Vrba 1985, 1995; Potts 1998a, b). On a smaller scale, it is evident that early Homo populations experienced environmental variability.

The cooler Plio-Pleistocene climate opened up the African forests to the kinds of savanna grasslands that are now widespread in sub-Saharan Africa. These early savannas were populated with large grazing herbivores that became regular meals for $H$. erectus - probably the first hominin to be keenly adapted to these non-forested environments (Reed 1997). Arid, seasonally wet and dry habitats were already occupied by earliest Homo between 2.5 and 2.0 million years ago, and after that hominins preferred increasingly open and wetter grasslands (Reed and Russak 2009). Butchered turtles, crocodiles, and fish at a 1.9 million years-old site in Koobi Fora (Braun et al. 2010) support this paleoenvironmental interpretation. Although this particular evidence predates $H$. erectus, analyses of Ethiopian and South African mammalian fossil assemblages - for example, reconstruction of community composition and biogeochemical analysis of tooth enamel- link the appearance and spread of $H$. erectus to a marked shift toward increased grasslands and, in general, more open and wetter landscapes (Bobe and Leakey 2009; Sponheinmer and Lee-Thorp 2009).

Further zooarchaeological evidence supports that $H$. erectus incorporated animal protein into its diet. Cut marks from stone tools on large mammal bones are distinct from marks left by the teeth of carnivores like big cats, and cutmarked and butchered bones increase in prevalence around the appearance of $H$. erectus and in association with Acheulean artifacts (Roche et al. 2009). The dispersal of the species beyond the African continent, the development of a much larger roaming range, and the increase in body size are consistent with a shift to a more carnivorous and possibly a predatory model for $H$. erectus behavior and biology (Shipman and Walker 1989).

These early scavengers and hunters did not yet behave completely like later species of Homo. With the earliest known evidence for fire use at about 780,000 years ago in Israel (Goren-Inbar et al. 2004), there is a long gap between the onset of meat-eating and evidence for cooking ability. Furthermore and as mentioned above, $H$. erectus may not have possessed the ability to successfully incorporate projectiles into its hunting strategy; although its body was adapted for bipedalism, its shoulder was not yet built for the complex and difficult task of overarm throwing (Larson et al. 2007). Moreover, there are no undisputed, specialized projectile weapons (like spears) associated with $H$. erectus. Anatomical, physiological, and behavioral adaptations for hunting and scavenging evolved over the past two million years from simple beginnings, which may perhaps be modeled after wild chimpanzees that thrust pointed sticks at sleeping prosimians (Pruetz and Bertolani 2007).

The ability to run for long distances would have been a tremendous advantage in scavenging and hunting, especially if $H$. erectus did not possess effective throwing ability. Hallmarks of the $H$. erectus skeleton such as long legs, a narrow flexible waist, and short forearms seem to be adaptations for such intense endurance activity, and these traits appear before the invention of sophisticated projectile hunting weapons (Bramble and Lieberman 2004; Lieberman et al. 2009). Other traits found in $H$. erectus fossils that are 
consistent with running adaptations including larger anterior and posterior semicircular canals (the parts of the inner ear that coordinate with the eyes to accommodate for head movement), a large attachment for the nuchal ligament on the back of the skull (to aid in head stability), larger gluteal muscles (as reconstructed from the bony pelvis), and enlarged lumbar vertebral bodies and leg joints (for withstanding impact; Bramble and Lieberman 2004; Lieberman et al. 2009). Adaptations for endurance running would also have benefited the evolution of throwing ability and may have been exaptive for humanlike throwing (Larson 2009).

Preserved footprints from the Ileret region east of Lake Turkana show that $H$. erectus feet were just as well designed for walking and running as the rest of the body (Bennett et al. 2009). Scavenging would have been easier with endurance running capabilities, but the success rate at hunting down medium-to-large game would have significantly improved thanks to persistence (Lieberman et al. 2009). With all of this foraging activity out on the open, sun-scorched savanna, it would have been imperative that $H$. erectus could regulate its temperature; this is when intense sweat cooling, aided by body fur loss, may have originated (Jablonski 2004). Molecular phylogenetics of body lice (Reed et al. 2007) or another innovative research avenue may soon provide a date for the drastic reduction of body fur in hominins.

\section{Current Debates}

\section{What Exactly Is the Genus Homo?}

Part of what inhibits a consensus on what constitutes the genus Homo (and this applies to debates about the validity of many fossil taxa) is the fact that, as in all of the great apes, there are no new discrete anatomical traits that appear or disappear in Homo - at least none that fossilize - that were absent or present in preceding hominins. There are only new trends in Homo. With no exclusive differences by which to distinguish Homo from earlier hominins, the node connecting their separate evolutionary branches is blurry, and with each new discovery, it becomes blurrier.

Some early Homo fossils (and early Homo candidates) link to some dental traits of australopiths and some postcranial traits of later Homo, while others link to some dental traits of Homo yet retain more primitive postcranial morphology. Some isolated teeth and jaws look more primitive while others look more derived. It is difficult to sort out the evolutionary relationships of early Homo fossils.

As a result, there is some disagreement regarding the genus attribution of the habilis and rudolfensis material and, by extension, the definition of the genus Homo. Under a new definition of Homo offered by Wood and Collard (1999; Wood 2009), all members display traits of a single adaptive complex that are manifested in body size and shape, locomotion, and relative size of the teeth and jaws. Therefore, if fossils designated as Homo must be more like humans than australopiths, then, according to some researchers, specimens belonging to $H$. habilis and $H$. rudolfensis fit better in Australopithecus. If this scheme is followed, then H. erectus fossils are the earliest Homo on record.

However, as $H$. habilis remains the best candidate ancestor for all later species of Homo, this is strong evidence for an ancestry or clade-based definition of the genus that includes habilis (Kimbel 2009). This scheme is still currently followed by the majority of paleontologists. It is not yet clear if any of the traits of the aforementioned adaptive complex were significant to the origin of the genus Homo, but that does not diminish the evidence or weaken the case for its start at the end of the Pliocene (Kimbel 2009).

How Much Overlap Between Species and How Much Variation Within Species?

In 2007, Spoor et al. (2007) announced two fossils from the site of Ileret, Kenya, on the eastern side of Lake Turkana. One was a $H$. erectus cranium (KNM-ER 42700) and the other a H. habilis maxilla (KNM-ER 42703), and they each contributed toward a potentially new understanding of early Homo.

First, the $H$. habilis maxilla, from 1.4 million years ago, extends the known existence of that species 400,000 years past the first appearance of $H$. erectus. As long as the maxilla really is $H$. habilis, then this implies that the two species lived sympatrically (living the same place) in the Turkana Basin for a half-million years and that all that separated the smaller-bodied H. habilis from the bigger $H$. erectus may have been a dietary or foraging difference.

Under a Darwinian model of speciation, one would expect to find that some $H$. habilis would continue evolving after a small subpopulation had branched off to later become $H$. erectus. However, these fossils represent another example of separate hominin species preferring similar geographic regions and potentially similar environments. Obviously there is no such species overlap today, but in our evolutionary past, there were at least three instances where two or more hominins most likely overlapped in space and time: (a) robust australopiths (Paranthropus) and early Homo in East and South Africa, (b) Neanderthals and $H$. sapiens in Europe, and (c) Homo floresiensis (the so-called "hobbits") and H. sapiens in Indonesia. Now, with the new Ileret finds, $H$. habilis and $H$. erectus may be added to that list. 
The morphology of the second fossil announced by Spoor et al. as the $H$. erectus cranium opens up a completely different can of worms. It is small and primitive. Thus, if it is indeed $H$. erectus, it expands the known range of variation on the small end for the species. However, its attribution to $H$. erectus has been questioned (Baab 2008b).

Understanding the level of variation within $H$. erectus is important for many reasons, one being the estimation of sexual dimorphism - a trait that has major implications for how we reconstruct social and reproductive behavior. Along the hominin evolutionary path, sexual dimorphism has decreased. Males and females were more disparate in body size than men and women are today, implying that past hominin social and reproductive strategies were apelike in comparison to ours. Until recently, it was assumed that the modern level of sexual dimorphismwith males and females being fairly similar in body size and tooth size - was achieved by $H$. erectus. New discoveries like the Ileret cranium, which is smaller than regional and contemporaneous conspecifics, and like the small Dmanisi individuals which show a large size range within a single species (Baab 2008b; Rightmire and Lordkipanidze 2009; but see Gabunia et al. 2002) are causing scholars to rethink traditional assumptions about $H$. erectus sexual dimorphism.

Once hominins achieve modern human levels of dimorphism, it may be hypothesized that modern reproductive strategies evolved as well. Normally pair-bonding between a male and female - including a particularly large increase in paternal investment as compared to previous hominins and to extant primates - is deemed necessary to raise highly vulnerable offspring such as large-brained, vulnerable, and slow-to-mature babies, like human babies. Pair-bonded primates tend to have low levels of sexual dimorphism since male-male competition for mates is decreased. However, with relatively small brains compared to modern humans, $H$. erectus young were not growing up as slowly as humans (Dean and Smith 2009), so selection may not yet have favored increased paternal investment and pairbonding behavior. If researchers determine that $H$. erectus had higher levels of sexual dimorphism than modern humans, then this will imply that they experienced higher male-male competition for mates than our more recent ancestors. However, until there are sufficient numbers of specimens recovered from sufficient numbers of sitesboth from similar ages and regions and also across time and space — such an estimate will be difficult to establish firmly.

\section{Did H. erectus Originate Outside of Africa?}

Based on geochronology of volcanic rocks at the site, the $H$. erectus fossils from Dmanisi, Georgia have been dated to about 1.78 million years ago (Gabunia et al. 2000). The site of Mojokerto in Indonesia may be just as old (Swisher et al.
1994; Huffman et al. 2006); and, along with Dmanisi, these sites preserve the early appearances of $H$. erectus outside of Africa. Remarkably, their ages coincide with the first appearance of $H$. erectus within Africa (e.g., the cranium KNM-ER 3733 dated to about 1.78 million years ago; Feibel et al. 1989), where the taxon presumably originated.

The Dmanisi fossils (Fig. 6), although attributed to $H$. erectus, do not share some key features with conspecifics in Africa and Asia, yet they do share some primitive features with H. habilis, like KNM-ER 1813 and OH 13 (Rightmire and Lordkipanidze 2009). This interpretation supports the hypothesis that $H$. erectus descended from $H$. habilis. However, there is a new hypothesis for the biogeographical origins of $H$. erectus based on the morphological affinities of the Dmanisi fossils: Since the Dmanisi hominins appear to have been the first post- $H$. habilis hominins to disperse out of East Africa, H. erectus evolved outside of Africa, possibly in western Asia (Rightmire and Lordkipanidze 2009). The early dates in Indonesia could be taken to support this hypothesis and, potentially, so can new $H$. erectus remains dated to 1.7 million years ago from the Yuanmou Basin in southwest China (Zhu et al. 2008).

\section{Did Primitive Homo Survive into the Late Pleistocene?}

In 2004, Australian and Indonesian researchers, working at the Liang Bua cave on the island of Flores, Indonesia, announced an enigmatic new hominin they called $H$. floresiensis (Brown et al. 2004; Morwood et al. 2005). The new species, which lived between 94 and 17,000 years ago, is represented by the small-bodied skeletal and dental remains of at least nine and as many as 14 individuals, most notably by the wellpreserved partial skeleton known as LB1. For the last six years since the discovery, a lively debate has persisted over the remains due to their many surprising traits. Hypotheses that the remains are diseased and are not representative of a new species have circulated in the literature. However, a

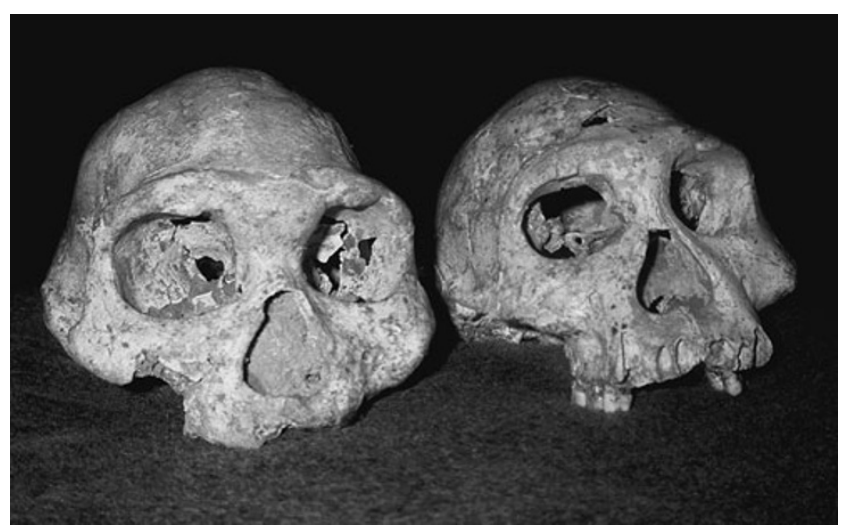

Fig. 6 Two of the excellently preserved skulls discovered at the early Pleistocene site of Dmanisi, Georgia. D 3444 is on the left and D 2700 is on the right. Photograph by the author 
recent review of all of the current available evidence finds that the Liang Bua hominins are indeed a late-surviving species of early pre- $H$. erectus (Aiello 2010).

The strikingly small stature of LB1, reaching only 1.06 meters tall, as a full-grown adult, earned it the nickname of "hobbit" after the small-bodied people in J. R. R. Tolkien's novels. Not only is LB1 far smaller than all modern adult humans including pygmies, it is similar in size to the famous partial skeleton of the A. afarensis known as "Lucy"- a fossil over three million years older than LB1. What is even more surprising is the cranial capacity of LB1, as the brain is estimated to be only between 385 and 417 cubic centimeters (Falk et al. 2005a), which is on par with the smallest australopiths.

The tiny brain of the single preserved cranium has led some to suggest that the best explanation for LB1 is that it suffered from microcephaly - a pathologically small brain that can be caused by a number of genetic and developmental abnormalities. However, the brain shape of LB1 (as digitally reconstructed from the endocasts of the cranium), although small, appears to be normal (for some of this debate, see Aiello 2010; Falk et al. 2005a, b; Martin et al. 2006). Relatively little is known about microcephaly, but based on the skulls and radiographs available for people affected with the condition, the shape of the brain is usually altered from that of normally-developed brains. Other individuals from Liang Bua are small like LB1, but unfortunately, none has a preserved skull to allow brain size estimation.

Despite issues of body and brain size (which have been traditionally important for identifying Homo), the discovery team placed the Liang Bua remains in the genus Homo. The tooth, jaw, face, and cranial anatomy resemble that of $H$. erectus, and the associated archaeological evidence (like advanced tools and evidence of hunting and fire use) indicates behavioral complexity. To explain the small stature of these hominins, the discoverers offered the following hypothesis: $H$. floresiensis descended from a population of $H$. erectus living in Indonesia, and their small bodies are the result of long-term isolation and ecological pressures specific to islands. Island dwarfism is not very well understood, but patterns of animal body sizes around the world reveal that island ecology sometimes influences body size. Small animals sometimes grow large on islands compared to their relatives on the mainland, because predator pressure is relaxed. But large animals tend to get smaller because islands have limited resources. The giant rats of Flores are a good example of the former, and the extinct miniature elephants of Flores probably reflect the latter. H. floresiensis could be a descendant of $H$. erectus that survived on Flores the same way that elephants did; it got small.

The problem with the insular dwarfing hypothesis is it that it does not quite explain why the Liang Bua hominins do not look like scaled down $H$. erectus. Instead, for example, the carpals, or wrist bones, are primitive and apelike (Tocheri et al. 2007), the feet are large (Jungers et al. 2009a), and the long upper extremities and short legs echo the limb proportions of "Lucy" A.L. 288-1 (Jungers 2009; Jungers et al. 2009b). As researchers continue to perform in-depth analyses of the bones, the results strengthen the other initial hypothesis, which is that the Liang Bua hominins descended from a population that dispersed from Africa prior to the evolution of $H$. erectus.

\section{Summary}

The origin of the genus Homo in Africa signals the beginning of the shift from increasingly bipedal apes to primitive, largebrained, stone tool-making, meat-eaters that traveled far and wide. This early part of the human genus is represented by three species: H. habilis, H. rudolfensis, and $H$. erectus. $H$. habilis is known for retaining primitive features that link it to australopiths and for being the first stone tool makers. Little is known about $H$. rudolfensis except that it had a relatively large brain and large teeth compared to H. habilis and that it overlapped in time and space with other early Homo. Our understanding of the paleobiology and evolution of the largerbrained $H$. erectus is enhanced due to its richer fossil record. $H$. erectus was the first obligate, fully committed biped, and with a body adapted for modern striding locomotion, it was also the first in the human lineage to disperse outside of Africa. New discoveries controversially hint that the origin of $H$. erectus may not have been African, as is the prevailing hypothesis, and, furthermore, diminutive and primitive hominins from Flores may be descendants of an even earlier dispersal of Homo than $H$. erectus. In spite of all the questions that remain to be answered about early Homo, these hominins are the first to tip the scale from the more apish side of our evolutionary history toward the more human one.

Acknowledgments I am grateful to William Harcourt-Smith for giving me the opportunity to write this paper and also to Kevin Stacey, Christopher Bae, and two anonymous reviewers for their help in improving an earlier version of the manuscript. I am also pleased to be indebted to Susan Antón, Nina Jablonski, Pat Shipman, and Alan Walker for sharing their wisdom about early Homo with me.

\section{References}

Aiello LC. Five years of Homo floresiensis. Am J Phys Anthropol. 2010;142:167-79.

Antón SC. Natural history of Homo erectus. Yrbk Phys Anthropol. 2003;46:126-70.

Arambourg C. L'hominien fossile de Ternifine (Algérie). Comptes rendus de l'Académie des Sciences de Paris. 1954;239:893-5.

Arambourg C. A recent discovery in human paleontology: Atlanthropus of Ternifine (Algeria). Am J Phys Anthropol. 1955;13:191-201. 
Arambourg C, Biberson P. The fossil human remains from the Paleolithic site of Sidi Abderrahman (Morocco). Am J Phys Anthropol. 1956;14:467-90.

Asfaw B, White T, Lovejoy O, Latimer B, Simpson S, Suwa G. Australopithecus garhi: a new species of early hominin from Ethiopia. Science. 1999;284:629-35.

Baab KL. The taxonomic implications of cranial shape variation in Homo erectus. J Hum Evol. 2008a;54:827-47.

Baab KL. A re-evaluation of the taxonomic affinities of the early Homo cranium KNM-ER 42700. J Hum Evol. 2008b;55:741-6.

Bennett MR, Harris JWK, Richmond BG, Braun DR, Muba E, Kiura $\mathrm{P}$, et al. Early hominin foot morphology based on 1.5-millionyear-old footprints from Ileret, Kenya. Science. 2009;323 (5918):1197-201.

Berger LR, de Ruiter DJ, Churchill SE, Schmid P, Carlson KJ, Dirks PHGM, et al. Australopithecus sediba: a new species of Homolike australopith from South Africa. Science. 2010;328:195-204.

Bingham PM. Human uniqueness: a general theory. Q Rev Biol. 1999;74:122-69.

Black D. On a lower molar hominid tooth from the Chou Kou Tien deposit. Palaeontol Sin Ser D. 1927;7:1

Black D. The Croonian lecture: on the discovery, morphology and environment of Sinanthropus pekinensis. Philos Trans R Soc B. 1933;223:57-120.

Blumenschine RJ, Peters CR, Masao FT, Clarke RJ, Deino AL, Hay $\mathrm{RL}$, et al. Late Pliocene Homo and hominid land use from western Olduvai Gorge, Tanzania. Science. 2003;299:1217-21.

Bobe R, Leakey MG. Ecology of the Plio-Pleistocene mammals in the Omo-Turkana Basin and the emergence of Homo. In: Grine F et al., editors. The first humans - origin and early evolution of the genus Homo. Berlin: Springer; 2009. p. 173-84.

Bramble DM, Lieberman DE. Endurance running and the evolution of Homo. Nature. 2004;432:345-52.

Braun DR, Plummer T, Ditchfield P, Ferraro JV, Maina D, Bishop LC, et al. Oldowan behavior and raw material transport: perspectives from the Kanjera formation. J Arch Sci. 2008a;35:2329-45.

Braun DR, Tactikos JC, Ferraro JV, Arnow SL, Harris JWK. Oldowan reduction sequences: methodological considerations. J Arch Sci. 2008b;35:2153-63.

Braun DR, Harris JWK, Levin NE, McCoy JT, Herries AIR, Bishop BMK, et al. Early hominin diet included diverse terrestrial and aquatic animals $1.95 \mathrm{Ma}$ in East Turkana, Kenya. PNAS. 2010;107(22):10002-7.

Brown F, Harris J, Leakey R, Walker A. Early Homo erectus skeleton from west Lake Turkana, Kenya. Nature. 1985;316:788-92.

Brown P, Sutikna T, Morwood MJ, Soejono RP, Jatmiko, Wayhu, et al. A new small-bodied hominin from the Late Pleistocene of Flores Indonesia. Nature. 2004;431:1055-61.

Calvin WH. The throwing Madonna: essays on the brain. New York: Bantam; 1983.

Carlson K, Wrangham R, Muller M, Sumner R, Morbeck ME, Nishida $\mathrm{T}$, et al. The locomotor repertoire of early Homo: insights from chimpanzee variation. Am J Phys Anthropol. 2010;Suppl 50:42.

Clarke RJ, Howell FC, Brain CK. More evidence of an advanced hominid at Swartkrans. Nature. 1970;225:1219-22.

Day MH. Postcranial remains of Homo erectus from Bed IV, Olduvai Gorge, Tanzania. Nature. 1971;232:383-7.

Day MH. Guide to fossil man. 4th ed. Chicago: University of Chicago Press; 1986.

Day MH, Leakey REF. New evidence of the genus Homo from East Rudolf Kenya. III. Am J Phys Anthropol. 1974;41:367-80.

Day MH, Leakey REF, Walker AC, Wood BA. New hominids from East Rudolf Kenya. I. Am J Phys Anthropol. 1975;42:461-76.

de Heinzelin J, Clark JD, White T, Hart W, Renne P, WoldeGabriel G, et al. Environment and behavior of 2.5-million-year-old Bouri hominids. Science. 1999;284:625-9.
Dean MC, Smith BH. Growth and development of the Nariokotome youth, KNM-ET 15000. In: Grine F et al., editors. The first humans - origin and early evolution of the genus Homo. Berlin: Springer; 2009. p. 101-20.

Deino AL, Hill A. ${ }^{40} \mathrm{Ar} /{ }^{39} \mathrm{Ar}$ dating of Chemeron formation strata encompassing the site of hominin KNM-BC 1, Tugen Hills, Kenya. J Hum Evol. 2002;42:141-51.

deMenocal PB. African climate change and faunal evolution during the Pliocene-Pleistocene. Earth Planet Sci Lett. 2004;220(1-2):3-24.

Dubois E. Pithecanthropus erectus, ein menschenahnliche Ubergangsform aus Java. Batavia: Landesdruckerei; 1894.

Dubois E. Figures of the calvarium and endocranial cast, a fragment of the mandible and three teeth of Pithecanthropus erectus. Proc K Ned Akad Wet. 1924;27:459-64.

Dunsworth HM. The identity of the Chemeron temporal. Am J Phys Anthropol. 2002;Suppl 34:65.

Dunsworth HM, Walker A. Early genus Homo. In: Hartwig W, editor. The primate fossil record. Cambridge: Cambridge University Press; 2002. p. 419-26.

Dunsworth HM, Challis JH, Walker A. Throwing and bipedalism: a new look at an old idea. In: Franzen JL, Dohler M, Moya-Sola S, editors. Upright walking. Frankfurt: Senckenberg Institute; 2003. p. $105-10$

Falk D, Hildebolt C, Smith K, Morwood MJ, Sutikna T, Brown P, et al. The brain of LB1, Homo floresiensis. Science. 2005a;308:242-5.

Falk D, Hildebolt C, Smith K, Morwood MJ, Sutikna T, Jatmiko, et al. Response to comment on "The brain of LB1 Homo floresiensis". Science. 2005b;310:236.

Feibel C, Brown FH, McDougall I. Stratigraphic context of fossil hominids from the Omo group deposits: Northern Turkana Basin, Kenya and Ethiopia. Am J Phys Anthropol. 1989;78(4):595-622.

Gabunia LK, Vekua A. A Plio-Pleistocene hominid from Dmanisi, East Georgia, Caucasus. Nature. 1995;373:509-12.

Gabunia L, Vekua A, Lordkipanidze D, Swisher CC, Ferring R, Justus A, et al. Earliest Pleistocene hominid cranial remains from Dmanisi, Republic of Georgia: taxonomy, geological setting, and age. Science. 2000;288(5468):1019-25.

Gabunia L, Vekua AK, de Lumly MA, Lordkipanidze D. A new species of Homo represented by a fossil from the bottom part of the Pleistocene layer at Dmanisi, Georgia. Archaeol Ethnol Anthropol Eurasia. 2002;4:145-52.

Gibbons A. Human ancestor caught in the midst of a makeover. Science. 2010;328:413

Goren-Inbar N, Alperson N, Kislev ME, Simchoni O, Melamed Y, Ben-Nun A, et al. Evidence of hominin control of fire at Gesher Benot Ya`aqov, Israel. Science. 2004;304(5671):725-7.

Graves RR, McCarthy RC, Lupo AC, Wescott DJ, Cunningham DL. New estimates of stature and body mass for KNM-WT 15000 . Am J Phys Anthropol. 2010;Suppl 50:106-7.

Grine FE, Fleagle JG. The first humans: a summary perspective on the origin and early evolution of the genus Homo. In: Grine F et al., editors. The first humans - origin and early evolution of the genus Homo. Berlin: Springer; 2009. p. 197-207.

Hill A, Ward S, Deino A, Curtis G, Drake R. Earliest Homo. Nature. 1992;355:719-22.

Holloway RL. Human paleontological evidence relevant to language behavior. Hum Neurobiol. 1983;2:105-14.

Holloway R. Brain. In: Delson E et al., editors. Encyclopedia of human evolution and prehistory. New York: Garland; 2000. p. 141-9.

Hou YM, Potts R, Yuan BY, et al. Mid-Pleistocene Acheulean-like stone technology of the Bose Basin, South China. Science. 2000;287:1622-6.

Howell FC. Pliocene/Pleistocene Hominidae in eastern Africa: absolute and relative ages. In: Bishop WW, Miller JA, editors. Calibration of hominoid evolution. Edinburgh: Scottish Academic; 1972. p. 331-68. 
Howell FC. Hominidae. In: Maglio VJ, Cooke HBS, editors. Evolution of African mammals. Cambridge: Harvard University Press; 1978. p. 154-248.

Huffman OF, Zaim Y, Kappelman J, Ruez DR Jr, de Vos J, Rizal Y, et al. Relocation of the 1936 Mojokerto skull discovery site near Perning, East Java. J Hum Evol. 2006;50:431-51.

Hughes AR, Tobias PV. A fossil skull probably of the genus Homo from Sterkfontein, Transvaal. Nature. 1977;265:310-2.

Indriati E, Swisher CC III, Lepre C, Quinn RL, Suriyanto RA, Hascaryo AT, et al. The age of the 20 meter Solo River Terrace, Ngandong (Java, Indonesia) reconsidered. Am J Phys Anthropol. 2010;Suppl 50:135.

Jablonski NG. The evolution of human skin and skin color. Ann Rev Anthropol. 2004;33:585-623.

Johanson DC, Masao FT, Eck GG, White TD, Walter RC, Kimbel WH, et al. New partial skeleton of Homo habilis from Olduvai Gorge, Tanzania. Nature. 1987;327:205-9.

Jungers WL. Interlimb proportions in humans and fossil hominins: variability and scaling. In: Grine $\mathrm{F}$ et al., editors. The first humans - origin and early evolution of the genus Homo. Berlin: Springer; 2009. p. 93-8.

Jungers WL, Harcourt-Smith WEH, Wunderlich RE, Tocheri MW, Larson SG, Sutikna T, et al. The foot of Homo floresiensis. Nature. 2009a;459:81-4.

Jungers WL, Larson SG, Harcourt-Smith W, Morwood MJ, Sutikna T, Awe Due R, et al. Descriptions of the lower limb skeleton of Homo floresiensis. J Hum Evol. 2009b;57:538-54.

Kimbel WH. The origin of Homo. In: Grine F et al., editors. The first humans - origin and early evolution of the genus Homo. Berlin: Springer; 2009. p. 31-7.

Kimbel WH, Walter RC, Johanson DC, Reed KE, Aronson JL, Assefa Z, et al. Late Pliocene Homo and Oldowan tools from the Hadar Formation (Kada Hadar Member), Ethiopia. J Hum Evol. 1996;31:549-61.

Larson SG. Evolution of the hominin shoulder: early Homo. In: Grine $F$ et al., editors. The first humans - origin and early evolution of the genus Homo. Berlin: Springer; 2009. p. 65-75.

Larson SG, Jungers WL, Morwood MJ, Sutikna T, Jatmiko SEW, Due RA, et al. Homo floresiensis and the evolution of the hominin shoulder. J Hum Evol. 2007;53(6):718-31.

Leakey LSB. New finds at Olduvai Gorge. Nature. 1961;189:649-50.

Leakey MD. Discovery of postcranial remains of Homo erectus and associated artifacts in Bed IV at Olduvai Gorge, Tanzania. Nature. 1971;232:380-3.

Leakey REF. Further evidence of lower Pleistocene hominids from East Rudolf, North Kenya, 1972. Nature. 1973a;242:170-3.

Leakey REF. Evidence for an advanced Plio-Pleistocene hominid from East Rudolf, Kenya. Nature. 1973b;242:447-50.

Leakey REF. Further evidence of lower Pleistocene hominids from East Rudolf, North Kenya, 1973. Nature. 1974;248:653-6.

Leakey REF. New hominid fossils from the Koobi Fora formation in Northern Kenya. Nature. 1976;261:574-6.

Leakey LSB, Leakey MD. Recent discoveries of fossil hominids in Tanganyika: at Olduvai and near Lake Natron. Nature. 1964;202:5-7.

Leakey REF, Wood BA. New evidence of the genus Homo from East Rudolf Kenya. II. Am J Phys Anthropol. 1973;39:355-68.

Leakey LSB, Tobias PV, Napier JR. A new species of the genus Homo from Olduvai Gorge. Nature. 1964;202:7-9.

Leakey MD, Clarke RJ, Leakey LSB. New hominid skull from Bed I, Olduvai Gorge, Tanzania. Nature. 1971;232:308-12.

Lieberman DE, Bramble DM, Raichlen DA, Shea JJ. Brains, brawn, and the evolution of human endurance running capabilities. In: Grine F et al., editors. The first humans - origin and early evolution of the genus Homo. Berlin: Springer; 2009. p. 77-92.

Lockwood C, Kimbel W, Lynch J. Temporal bone morphology and earliest Homo. Am J Phys Anthropol. 2002;Suppl 34:102-3.
Lordkipanidze D, Vekua A, Ferring R, Rightmire GP, Agusti J, Kiladze $G$, et al. The earliest toothless hominin skull. Nature. 2005;434:717-8.

Lordkipanidze D, Jashashvili T, Vekua A, Ponce de León MS, Zollikofer CPE, Rightmire GP, et al. Postcranial evidence from early Homo from Dmanisi, Georgia. Nature. 2007;449:305-10.

Martin RD, Maclarnon AM, Phillips JL, Dussubieux L, Williams PR, Dobyns WB. Comment on "The brain of LB1 Homo floresiensis". Science. 2006;312:999.

Maslin MA, Trauth MH. Plio-Pleistocene East African pulsed climate variability and its influence on early human evolution. In: Grine F et al., editors. The first humans - origin and early evolution of the genus Homo. Berlin: Springer; 2009. p. 151-8.

Miller JA. Does brain size variability provide evidence of multiple species in Homo habilis? Am J Phys Anthropol. 1990;84(4):38598.

Morwood MJ, Brown P, Jatmiko, Sutikna T, Saptona EW, Westaway $\mathrm{KE}$, et al. Further evidence for small-bodied hominins from the Late Pleistocene of Flores Indonesia. Nature. 2005;437:1012-7.

Movius HL. The Lower Palaeolithic cultures of southern and eastern Asia. Trans Am Philos Soc. 1948;38:329-420.

Norton (Bae) CJ, Bae K. The Movius Line sensu lato (Norton et al. 2006) further assessed and defined. J Hum Evol. 2008;55:114850.

Ohman JC, Wood C, Wood B, Crompton RH, Günther MM, Yu L, et al. Stature-at-death of KNM-WT 15000. Hum Evol. 2000;17(34):129-41.

Petraglia MD, Shipton C. Large cutting tool variation west and east of the Movius Line. J Hum Evol. 2008;55:962-6.

Potts R. Environmental hypotheses of hominin evolution. Yrbk Phys Anthropol. 1998a;41:93-136.

Potts R. Variability selection in hominid evolution. Evol Anthropol. 1998b;7:81-96.

Pruetz JD, Bertolani P. Savanna chimpanzees, Pan troglodytes verus, hunt with tools. Curr Biol. 2007;17:1-6.

Reed KE. Early hominid evolution and ecological change through the African Plio-Pleistocene. J Hum Evol. 1997;32:289-322.

Reed KE, Russak SM. Tracking ecological change in relation to the emergence of Homo near the Plio-Pleistocene boundary. In: Grine F et al., editors. The first humans - origin and early evolution of the genus Homo. Berlin: Springer; 2009. p. 159-71.

Reed DL, Light JE, Allen JM, Kirchman JJ. Pair of lice lost or parasites regained: the evolutionary history of anthropoid primate lice. BMC Biol. 2007;5:7.

Rightmire GP, Lordkipanidze D. Comparisons of early Pleistocene skulls from East Africa and the Georgian Caucasus: evidence bearing on the origin and systematics of genus Homo. In: Grine F et al., editors. The first humans - origin and early evolution of the genus Homo. Berlin: Springer; 2009. p. 39-48.

Rightmire GP, Lordkipanidze D, Vekua A. Anatomical descriptions, comparative studies and evolutionary significance of the hominin skulls from Dmanisi, Republic of Georgia. J Hum Evol. 2006;50 (2): $115-41$.

Roche H, Blumenschine RJ, Shea JJ. Origins and adaptations of early Homo: what archaeology tells us. In: Grine F et al., editors. The first humans - origin and early evolution of the genus Homo. Berlin: Springer; 2009. p. 135-47.

Ruff C. Relative limb strength and locomotion in Homo habilis. Am J Phys Anthropol. 2009;138:90-100.

Ruff CB, Trinkaus E, Holliday TW. Body mass and encephalization in Pleistocene Homo. Nature. 1997;387:173-6.

Sartono S. Discovery of another hominid skull at Sangiran, Central Java. Curr Anthropol. 1972;13(1):124-5.

Semaw S, Renne P, Harris JWK, Feibel CS, Bernor RL, Fesseha N, et al. 2.5-million-year-old stone tools from Gona, Ethiopia. Science. 1997;284:625-9. 
Semaw S, Rogers MJ, Quade J, Renne PR, Butler RF, DominguezRodrigo M, et al. 2.6-million-year-old stone tools and associated bones from OGS-6 and OGS-7, Gona, Afar, Ethiopia. J Hum Evol. 2003;45(2):169-77.

Shen G, Gao X, Gao B, Granger DE. Age of Zhoukoudian Homo erectus determined with ${ }^{26} \mathrm{Al} /{ }^{10} \mathrm{Be}$ burial dating. Nature. 2009;458:198-200.

Sherwood RJ, Ward SC, Hill A. The taxonomic status of the Chemeron temporal (KNM-BC 1). J Hum Evol. 2002;42:153-84.

Shipman P, Walker A. The costs of becoming a predator. J Hum Evol. 1989;18:373-92.

Sonakia A. The skull-cap of early man and associated mammalian fauna from Narmada Valley alluvium, Oasangabad Area, Madhya Pradsesh (India). Rec Geol Surv India. 1984;113:159-72.

Sponheinmer M, Lee-Thorp JA. Biogeochemical evidence for the environments of early Homo in South Africa. In: Grine F et al., editors. The first humans - origin and early evolution of the genus Homo. Berlin: Springer; 2009. p. 185-94.

Spoor F, Leakey M, Gathogo P, Brown F, Antón S, McDougall I, et al. Implications of new early Homo fossils from Ileret, east of Lake Turkana, Kenya. Nature. 2007;448:688-91.

Susman RL. Evidence bearing on the status of Homo habilis at Olduvai Gorge. Am J Phys Anthropol. 2008;137:356-61.

Swisher CC, Curtis GH, Jacob T, Getty AG, Suprijo A, Widiasmoro. Age of the earliest known hominids in Java, Indonesia. Science. 1994;263(5150):1118-21.

Swisher CC, Rink WJ, Antón SC, Schwarcz HP, Curtis GH, Suprijo A, et al. Latest Homo erectus of Java: potential contemporaneity with Homo sapiens in Southeast Asia. Science. 1996;274 (5294):1870-4.

Tattersall I. Homo ergaster and its contemporaries. In: Henke W, Tattersall I, editors. Handbook of paleoanthropology, 3 Vols. Berlin: Springer; 2007. p. 1633-53.

Tobias PV. Pleistocene deposits and new fossil localities in Kenya. Nature. 1967;215:476-80.

Tobias PV. Olduvai Gorge, vol 4. Cambridge: Cambridge University Press; 1991.

Tobias PV. Homo habilis - a premature discovery: remembered by one of its founding fathers, 42 years later. In: Grine F et al., editors.
The first humans - origin and early evolution of the genus Homo. Berlin: Springer; 2009. p. 7-15.

Tocheri MW, Orr CM, Larson SG, Sutikna T, Jatmiko, Saptomo EW, et al. The primitive wrist of Homo floresiensis and its implications for hominin evolution. Science. 2007;317:1743-5.

Ungar P. Dental topography and diets of Australopithecus afarensis and early Homo. J Hum Evol. 2004;46:605-22.

Unger PS, Scott RS. Dental evidence for diets of early Homo. In: Grine F et al., editors. The first humans - origin and early evolution of the genus Homo. Berlin: Springer; 2009. p. 121-34.

Vrba ES. Environment and evolution - alternative causes of the temporal distribution of evolutionary events. S Afr J Sci. 1985;81:229-36.

Vrba ES. On the connections between paleoclimate and evolution. In: Vrba ES et al., editors. Paleoclimate and evolution with emphasis on human origins. New Haven: Yale University Press; 1995.

Walker A, Leakey REF. The Nariokotome Homo erectus skeleton. Cambridge: Harvard University Press; 1993.

Wang W, Mo JY, Huang ZT. Recent discovery of handaxes associated with tektites in the Nanbanshan locality of the Damei site, Bose basin, Guangxi, South China. Chin Sci Bull. 2008;53(6):878-83.

Weidenreich F. The skull of Sinanthropus pekinensis: a comparative study on a primitive hominid skull. Palaeontol Sin New D. 1943;10:1-484.

Weidenreich F. Giant early man from Java and South China. Science. 1944;99:479-82.

Wood BA. Origin and evolution of the genus Homo. Nature. 1992;355:783-90.

Wood BA. Plio-Pleistocene hominins from the Baringo Region, Kenya. In: Andrews P, Banham P, editors. Late Cenozoic environments and hominid evolution: a tribute to Bill Bishop. London: Geological Society; 1999. p. 113-22.

Wood BA. Where does the genus Homo begin, and how would we know? In: Grine $\mathrm{F}$ et al., editors. The first humans - origin and early evolution of the genus Homo. Berlin: Springer; 2009. p. 17-28.

Wood B, Collard M. The human genus. Science. 1999;284:65-71.

Zhu RX, Potts R, Pan YX, Yao HT, Lu LQ, Zhao X, et al. Early evidence of the genus Homo in East Asia. J Hum Evol. 2008;55:1075-85. 